\title{
Pharmacokinetic Profile of Single and Repeated Oral Doses of MDMA in Squirrel Monkeys: Relationship to Lasting Effects on Brain Serotonin Neurons
}

\author{
Annis Mechan', Jie Yuan', George Hatzidimitriou', Rodney J Irvine', Una D McCann ${ }^{3}$ and \\ George A Ricaurte*,' \\ 'Department of Neurology, Johns Hopkins University School of Medicine, Baltimore, MD, USA; ${ }^{2}$ Clinical and Experimental Pharmacology, \\ University of Adelaide, Adelaide, SA, Australia; ${ }^{3}$ Department of Psychiatry and Behavioral Sciences, Johns Hopkins University School \\ of Medicine, Baltimore, MD, USA
}

\begin{abstract}
A large body of data indicates that ( \pm )3,4-methylenedioxymethamphetamine (MDMA, 'ecstasy') can damage brain serotonin neurons in animals. However, the relevance of these preclinical data to humans is uncertain, because doses and routes of administration used in animals have generally differed from those used by humans. Here, we examined the pharmacokinetic profile of MDMA in squirrel monkeys after different routes of administration, and explored the relationship between acute plasma MDMA concentrations after repeated oral dosing and subsequent brain serotonin deficits. Oral MDMA administration engendered a plasma profile of MDMA in squirrel monkeys resembling that seen in humans, although the half-life of MDMA in monkeys is shorter (3 vs 6-9h). MDMA was biotransformed into MDA, and the plasma ratio of MDA to MDMA was 3-5/I00, similar to that in humans. MDMA accumulation in squirrel monkeys was nonlinear, and plasma levels were highly correlated with regional brain serotonin deficits observed 2 weeks later. The present results indicate that plasma concentrations of MDMA shown here to produce lasting serotonergic deficits in squirrel monkeys overlap those reported by other laboratories in some recreational 'ecstasy' consumers, and are two to three times higher than those found in humans administered a single 100-150 mg dose of MDMA in a controlled setting. Additional studies are needed on the relative sensitivity of brain serotonin neurons to MDMA toxicity in humans and non-human primates, the pharmacokinetic parameter(s) of MDMA most closely linked to the neurotoxic process, and metabolites other than MDA that may play a role. Neuropsychopharmacology (2006) 3 I, 339-350. doi: I 0. I038/sj.npp. I 300808; published online 6 July 2005
\end{abstract}

Keywords: MDMA; serotonin; pharmacokinetics; plasma; amphetamines

\section{INTRODUCTION}

$( \pm) 3,4-$ Methylenedioxymethamphetamine (MDMA, 'ecstasy') has become a popular recreational drug in many developed countries (Degenhardt et al, 2004; EMCDDA, 2003; Johnston et al, 2004), with annual and lifetime use rates in the US now comparable to those of cocaine (Johnston et al, 2004). A large body of data, summarized below, indicates that MDMA has the potential to damage to brain serotonin (5-hydroxytryptamine, 5-HT) neurons in various animal species, including non-human primates (Steele et al, 1994; Kalant, 2001; Green et al, 2003).

\footnotetext{
*Correspondence: Dr GA Ricaurte, Department of Neurology, Johns Hopkins Medical Institutions, 5501 Hopkins Bayview Circle, AAC, Room 5B.7IB, Baltimore, MD 21224, USA, Tel: + I 410550 0993, Fax: + I 4I0 550 2005, E-mail: Ricaurte@jhmi.edu

Received 3 November 2004; revised 22 April 2005; accepted 27 April 2005

Online publication: 25 May 2005 at http://www.acnp.org/citations/ Npp0525050405 I 6/default.pdf
}

However, the clinical relevance of much of these preclinical data remains uncertain because doses and routes of administration used in animals have generally differed from those used by humans (Hegadoren et al, 1999; Cole and Sumnall, 2003).

MDMA's potential to damage brain 5-HT neurons first became apparent when Schmidt (1987) reported that animals treated with single doses of MDMA developed lasting reductions in various markers of brain 5-HT neurons. Numerous subsequent studies have shown that MDMA-treated animals developed long-term (2 weeks) depletions of brain 5-HT, its major metabolite, 5-hydroxyindoleacetic acid (5-HIAA), its rate-limiting enzyme, tryptophan hydroxylase (TPH), its membrane transporter (5-HTT), and its vesicular monoamine transporter, $\mathrm{VMAT}_{2}$ (see Steele et al, 1994; Gibb et al, 1994; Lew et al, 1997; Green et al, 2003, for reviews). Furthermore, morphologic studies reveal swollen, distorted, seemingly fragmented 5-HT immunoreactive (IR) axons within days of MDMA treatment, followed by marked, lasting reductions in 5-HT- 
IR axon density weeks later (O'Hearn et al, 1988; Ricaurte et al, 1988b; Wilson et al, 1993; Axt et al, 1994). Considered along with results of tract-tracing studies demonstrating that MDMA, like 5,7-dihydroxytryptamine (5,7-DHT), can produce lasting reductions in anterograde axonal transport (Callahan et al, 2001), neurochemical and anatomic data have led a number of investigators to conclude that MDMA has the potential to damage brain 5-HT axons and axon terminals (Schmidt, 1987; Battaglia et al, 1987; Ricaurte et al, 1988b; Slikker et al, 1988, 1989; Kleven et al, 1989; Wilson et al, 1989; Insel et al, 1989; Gibb et al, 1994; Axt et al, 1994; Lew et al, 1997; Green et al, 2003), without damaging 5-HT nerve cell bodies in the brain stem raphe nuclei. For reasons yet to be elucidated, the abovementioned toxic effects of MDMA on 5-HT nerve fibers, like those of 5-7-DHT (Rowland et al, 1993; Bendotti et al, 1994), are not consistently associated with a glial reaction or a positive silver staining response (Wilson et al, 1993; O'Callaghan and Miller, 1994; Pubill et al, 2003; Thomas et al, 2004).

Despite the fact that long-term effects of MDMA have been demonstrated in a number of different experimental animals including rats, guinea pigs, cats, squirrel monkeys, cynomologous monkeys, rhesus monkeys, and baboons (see Steele et al, 1994; Lew et al, 1997; Green et al, 2003, for reviews), their relevance to humans is uncertain. In particular, it is unclear if doses and dosing regimens of MDMA tested in animals translate to those used by humans. In addition to dose comparisons, questions about dosing parameters can be addressed, at least in part, by characterizing plasma concentrations of MDMA that produce longterm serotonergic deficits in animals and determining how these compare with those that develop in humans. The single previous study that measured plasma concentrations of MDMA in non-human primates (Bowyer et al, 2003) was not designed to simulate a human use pattern, but showed that repeated intramuscular $10 \mathrm{mg} / \mathrm{kg}$ doses of $d$-MDMA that led to profound loss of brain serotonergic neuronal markers were associated with approximately 10 -fold higher plasma MDMA concentrations than those typically seen in humans after single MDMA doses.

The purpose of the present studies was to further bridge the gap between controlled studies of MDMA's long-term effects in laboratory animals and recreational use of MDMA ('ecstasy') in the community. To this end, we used nonhuman primates and administered MDMA orally, using a schedule of drug administration intended to simulate human use patterns. Specifically, we characterized the pharmacokinetic profile of single and repeated MDMA doses, and examined the relationship between plasma drug concentrations that develop acutely and regional brain 5HT deficits observed in the same squirrel monkeys 2 weeks later.

\section{MATERIALS AND METHODS}

\section{Animals}

Adult squirrel monkeys (Saimiri sciureus) of both genders, ranging in weight from $0.63-1.42 \mathrm{~kg}$, were used. Animals were housed in pairs in standard steel cages, in an ambient temperature of $26 \pm 3^{\circ} \mathrm{C}$ and $20-40 \%$ humidity, with free access to food and water. The colony room was maintained on a $14: 10 \mathrm{~h}$ light: dark cycle (lights on: $0700 \mathrm{~h}$ ). The facilities for housing and care of the animals are accredited by the American Association for the Assessment and Accreditation of Laboratory Animal Care. Animal care and experimental manipulations were approved by the Institutional Animal Care and Use Committee at the Johns Hopkins University School of Medicine, and were in accordance with the National Institutes of Health Guide for the Care and Use of Laboratory Animals.

\section{Drugs and Chemicals}

These were obtained from the following sources: $( \pm) 3,4$ methylenedioxymethamphetamine hydrochloride (MDMA) and ( \pm )3,4-methylenedioxyamphetamine $\mathrm{HCl}$ (MDA) (National Institute on Drug Abuse, Rockville, MD, USA), 5-hydroxytryptamine creatinine sulfate complex (5-HT), 5-hydroxyindoleacetic acid dicyclohexylammonium salt (5-HIAA), dopamine hydrochloride, 3,4-dihydroxyphenylacetic acid (DOPAC), sodium octyl sulfate, and ethylenediaminetetraacetic acid (EDTA) (Sigma-Aldrich, St Louis, MO, USA), sodium phosphate, citric acid, phosphoric acid, perchloric acid, and sodium chloride $(\mathrm{NaCl})$ (JT Baker, Phillipsburg, NJ, USA). The authenticity of the MDMA sample used in the present studies was confirmed using gas chromatographic/mass spectroscopic methods. For administration, MDMA was dissolved in normal saline $(\mathrm{NaCl}$; $0.9 \% \mathrm{w} / \mathrm{v}$ ) at a volume of $1 \mathrm{ml} / \mathrm{kg}$, and doses are expressed as the salt weight, unless otherwise stated.

\section{Single Dose/Route of Administration Study}

Oral vs subcutaneous dosing. For this experiment, four squirrel monkeys were used. Three of the four animals had participated in prior substituted amphetamine toxicity studies (Table 1); all other experiments reported in this

Table I Information on Drug Treatment of Squirrel Monkeys Used in Initial Study Comparing the Pharmacokinetic Profile of MDMA after Subcutaneous (s.c.) and Oral (p.o.) Administration

\begin{tabular}{|c|c|c|c|}
\hline Monkey & $\begin{array}{l}\text { Time interval } \\
\text { between single } \\
\text { s.c. and p.o. } \\
\text { doses (weeks) }\end{array}$ & $\begin{array}{l}\text { Time elapsed } \\
\text { since prior drug } \\
\text { treatment } \\
\text { (weeks) }\end{array}$ & Prior treatment \\
\hline I & 11.5 & 63 & $\begin{array}{l}\text { MDMA } \\
2 \mathrm{mg} / \mathrm{kg} \text {, every } 3 \mathrm{~h} \times 3\end{array}$ \\
\hline 2 & 7 & 9.5 & $\begin{array}{l}\text { MDMA } \\
2 \mathrm{mg} / \mathrm{kg} \text {, every } 3 \mathrm{~h} \times 3\end{array}$ \\
\hline 3 & 10 & 204 & $\begin{array}{l}\text { MDMA } \\
5 \mathrm{mg} / \mathrm{kg} \text {, twice daily } \times 4\end{array}$ \\
\hline 4 & 4 & $\begin{array}{l}\text { No prior drug } \\
\text { treatment }\end{array}$ & None \\
\hline
\end{tabular}

Both routes of administration were tested in the same four animals, with subcutaneous administration always preceding oral administration. The time interval between s.c. and p.o administration of single dose of MDMA was, on average, approximately 8 weeks (times for each animal are shown above). Three of the four monkeys used in this experiment had prior drug exposure. For these animals, the time elapsed since their prior drug treatment is shown, along with the drug used. On average, these animals had not been treated with any other drug for approximately 92 weeks. 
paper used drug-naive animals. Animals with a history of substituted amphetamine exposure were used for this initial experiment because the primary outcome measures were plasma concentrations of MDMA and MDA, rather than measures of 5-HT neurotoxicity, and, to our knowledge, there is no evidence that remote (in the present case, $92 \pm 100$ weeks; range: $9.5-203$ weeks) prior exposure to MDMA or its analogs alters its pharmacokinetic profile. Further, since a goal of the study was to compare the pharmacokinetics of MDMA in squirrel monkeys to those in humans in controlled studies, which invariably require previous MDMA exposure, use of animals with prior MDMA exposure was deemed reasonable. For this experiment, each monkey received two doses of MDMA (on average, 8 weeks apart, Table 1), one dose being administered subcutaneously (s.c.) and the second orally by gavage (p.o.).

In all cases, subcutaneous administration preceded oral administration, with an average of 8 weeks between s.c. and p.o. dosing. For subcutaneous administration, drug solution was injected under the skin in the midscapular region. For oral administration, animals were placed in a plexiglass restraining chair, and a number 8 French feeding tube was inserted and used to administer the drug orogastrically. Mean $( \pm S E M)$ doses used for this experiment were $7.32 \pm 0.32 \mathrm{mg} / \mathrm{kg}$; s.c. and $7.40 \pm 0.29 \mathrm{mg} / \mathrm{kg}$; p.o., calculated to be 'equivalent' to approximately a $2 \mathrm{mg} / \mathrm{kg}$ dose in a $70 \mathrm{~kg}$ human being, using interspecies dose scaling methods (for discussion of these methods, including their limitations, see Mordenti and Chappell, 1989; Ings, 1990; Boxenbaum and DiLea, 1995; Mahmood, 1999, 2002; Mahmood et al, 2003). Each monkey was administered a dose calculated using their individual weight at the time of administration. The fact that the mean dose differed slightly between s.c. and p.o. administration was due to slight differences in individual animal weights at the times of the two drug treatments. Blood from control and experimental animals was assayed in parallel.

\section{Repeated Oral Dose Studies}

Drug-naive monkeys were used in studies designed to test the neurotoxic potential of sequential oral MDMA doses, intended to simulate a recreational use pattern (Weir, 2000; Irvine et al, 2003; Parrott, 2005). In the first study, 15 monkeys were treated with MDMA and five untreated animals served as controls. For this experiment, separate groups of monkeys were administered a total of three equal doses of MDMA, at $3 \mathrm{~h}$ intervals, at one of four dosing levels $(2.4,4.3,6.4$, or $8.6 \mathrm{mg} / \mathrm{kg})$. As indicated above, we selected a $3 \mathrm{~h}$ dosing interval to simulate the dosing interval used by humans at dance parties, where it is not uncommon for individuals to take multiple doses over a $12 \mathrm{~h}$ period (Weir, 2000; Irvine et al, 2003; Parrott, 2005). Given that the elimination half-life of MDMA in squirrel monkeys is approximately one-half of that in humans (see Results/ Discussion), use of a comparable dosing interval would tend to underestimate that amount of MDMA likely to accumulate in humans as a consequence of repeated MDMA ingestion. No lethality was observed at any of the lower dosing regimens tested $(2.4,4.3$, and $6.4 \mathrm{mg} / \mathrm{kg}$ regimens). After the highest dosing regimen tested $(8.6 \mathrm{mg} / \mathrm{kg})$, two of six animals died shortly after drug treatment, and one received only two of the three planned doses and was, therefore, excluded from the analysis.

In the second sequential oral dose study, designed to explore the relationship between dose regimens of MDMA, plasma profiles of MDMA (and MDA), and indexes of brain serotonergic toxicity, we used additional drug-naïve animals. For these studies, three additional groups of monkeys ( $n=3$ per group) were treated with three of the four dose regimens of MDMA used above $(2.4,4.3$, and $6.4 \mathrm{mg} / \mathrm{kg})$ and were compared to controls $(n=5)$. Plasma samples were obtained at various times after oral MDMA administration and analyzed for their content of MDMA and MDA; 2 weeks later, brains of the same animals were assessed to determine the status of serotonergic neuronal markers. Tissues from control and experimental animals were assayed in parallel.

In a third study involving repeated doses, designed to test the effect of two (instead of three) sequential doses, three drug-naïve squirrel monkeys received two equal doses of $4.3 \mathrm{mg} / \mathrm{kg}$. p.o., with a $3 \mathrm{~h}$ interval between the two doses. As in the second study described above, blood was collected at regular intervals after each dose for determination of plasma MDMA and MDA levels. After 2 weeks, the animals were killed for determination of regional brain 5-HT neuronal markers.

In a fourth study that tested for a possible confounding effect of isoflurane (see anesthesia, below) anesthesia on plasma MDMA/MDA concentrations, squirrel monkeys $(n=4)$ received MDMA by oral gavage at a dose of $3.6 \mathrm{mg} / \mathrm{kg}$, followed by plasma sampling with or without anesthesia. In anesthetized monkeys, blood was collected at regular intervals after MDMA administration for the determination of plasma MDMA and MDA concentrations. In unanesthetized monkeys (same four monkeys tested at least 4 weeks later), blood was collected only at the $2 \mathrm{~h}$ time point after MDMA administration. This particular time point was selected because results of an initial study in anesthetized monkeys showed that plasma levels of MDMA and MDA remained relatively stable from 1.5 to $3 \mathrm{~h}$ after a $3.6 \mathrm{mg} / \mathrm{kg}$ oral dose.

\section{Blood Sampling}

For collection of blood samples used in the determination of plasma drug concentrations, animals were removed from their home-cages, transported to a surgery suite in a metal carrying box, and anesthetized with isoflurane, as below. While under isoflurane anesthesia, the animals were lain on a heating pad (maintained at $37^{\circ} \mathrm{C}$ by circulating warm water via a heat therapy pump (Gaymar Industries Inc., Orchard Park, NY, USA)), and placed on a steel surgical table. Blood samples were collected at 5, 15, and $30 \mathrm{~min} ; 1,2$, $3,4,5$, and $6 \mathrm{~h}$ during single dose experiments, and at $30 \mathrm{~min} ; 1$, and $2 \mathrm{~h} 50 \mathrm{~min}$ after each dose during sequential dose experiments. At each time point, approximately 0.5$1.0 \mathrm{ml}$ of blood were withdrawn from the femoral vein using a disposable, sterile $3 \mathrm{ml}$ syringe and $23 \mathrm{G} 1^{\prime \prime}$ needle. Blood samples were dispensed into $5 \mathrm{ml}$ Vacutainer ${ }^{\circledR}$ haematology tubes, containing $0.057 \mathrm{ml} \mathrm{15 \%}$ EDTA solution (BectonDickinson, Franklin Lakes, NJ, USA), and stored on ice for up to $30 \mathrm{~min}$, until centrifuged. Samples were centrifuged at $1100 \mathrm{~g}$ for $10 \mathrm{~min}$ at $4^{\circ} \mathrm{C}$ (Sorvall RC2-B, Kendro Laboratory 
Products, Newtown, CT, USA), plasma was withdrawn using a 5 3/4 Pasteur pipette and decanted into a $1.5 \mathrm{ml}$ microcentrifuge tube. Sodium metabisulfite $(250 \mathrm{mM})$ was added at a volume of $30 \mathrm{cl} / \mathrm{ml}$ of plasma, as in Segura et al (2001) to minimize oxidation of the compounds of interest. Samples were vortexed for $10 \mathrm{~s}$, then stored at $-20^{\circ} \mathrm{C}$ until further processed.

\section{Plasma Preparation}

Prior to determination of plasma levels of MDMA and MDA, plasma samples were subjected to solid phase extraction (SPE), to enable plasma filtration and purification of the compounds of interest, following the method of Herráez-Hernández et al (2001).

\section{Determination of Concentrations of MDMA and MDA}

Plasma concentrations of MDMA and its metabolite, MDA, were determined using HPLC with fluorescence detection, following the method of Sadeghipour and Veuthey (1997), with minor modifications. Briefly, the mobile phase consisted of sodium phosphate $(20 \mathrm{mM})$, sodium octyl sulfate $(0.25 \mathrm{mM})$, and acetonitrile $(15 \% \mathrm{v} / \mathrm{v})$, and was adjusted to $\mathrm{pH} 3.8$ with phosphoric acid, filtered, and degassed. The flow rate was $1 \mathrm{ml} / \mathrm{min}$ and the HPLC system consisted of a pump (LC-6A, Shimadzu Scientific Instruments Inc., Columbia, MD, USA) linked to an automatic sample injector (Shimadzu SIL-10Ai; loop $50 \mu \mathrm{l}$ ) and a stainless steel base deactivated $\mathrm{C}_{18}$ column (NUCLEOSIL 100-5 $\mathrm{C}_{18}$ Nautilus, $250 \times 4.6 \mathrm{~mm}$, Macherey-Nagel Inc., Easton, PA, USA), stored at $40^{\circ} \mathrm{C}$ (Shimadzu CTO-6A column oven). Detection was performed using an RF-10AXL fluorescence detector (Shimadzu), operated at an excitation wavelength of $285 \mathrm{~nm}$ and emission wavelength of $320 \mathrm{~nm}$, and the emitted wavelengths were monitored via an integrator (Shimadzu Chromatopac C-R7A), which provided calculation of sample peak heights, thus enabling comparison with peak heights of external standards. As with neurochemical assays, samples from control and experimental animals were assayed in parallel.

\section{HPLC Determination of Regional Brain 5-HT and DA and Their Metabolites}

At 2 weeks after drug administration, regional brain levels of 5-HT and 5-HIAA, and striatal levels of DA and DOPAC, were determined via HPLC with electrochemical detection, as described previously (Ricaurte et al, 1992).

\section{5-HTT Binding}

The density of 5-HTT-binding sites in regional brain homogenates was determined with tritiated paroxetine, using previously described methods (Scanzello et al, 1993).

\section{Quantitative Autoradiography}

Half-hemisphere coronal sections $(20 \mathrm{~cm})$ at the level of the hippocampus were thaw-mounted onto gelatin-coated microscope slides and then labeled with $50 \mathrm{pM}\left[{ }^{125} \mathrm{I}\right] \mathrm{RTI}-$ 55 (Perkin-Elmer Life Sciences, Billeria, MA) by incubating for $60 \mathrm{~min}$ at room temperature. $\left[{ }^{125} \mathrm{I}\right] \mathrm{RTI}-55$ was used because it binds with high affinity to both DA and 5-HT transporters, and because it labels DA and 5-HT transporters in a region-specific manner, with the vast majority of RTI-55 binding in striatal regions (caudate, putamen) representing binding to DA transporters, and the bulk of RTI-55 binding in extra-striatal regions representing binding to 5-HT transporters (Laruelle et al, 1993; Staley et al, 2001). Thus, $\left[{ }^{125} \mathrm{I}\right] \mathrm{RTI}-55$ was an attractive ligand because it would concomitantly give us information on dopamine and 5-HT transporter binding in the same animal/section. Autoradiographs were digitized with a Dage CCD 72 camera and MCID Elite 6.0 image analysis system (Amersham Biosciences Niagara Inc, St Catherines, Ontario, Canada), as previously described (Fischer et al, 1995).

\section{Pharmacokinetic Parameters}

Peak plasma concentrations $\left(C_{\max }\right)$, times of peak plasma concentration $\left(T_{\max }\right)$, area under the concentration-time curve (AUC), and the elimination half-lives $\left(t_{1 / 2}\right)$ of MDMA were obtained using the software program WinNonlin ${ }^{\mathrm{TM}}$ (Pharsight Co., Mountain View, CA). Data were fitted to a noncompartmental model with first-order output and elimination.

\section{Anesthesia}

For all studies requiring collection of blood samples (except for a control study in which the possible confounding effect of anesthesia on plasma MDMA and MDA levels was examined), isoflurane anesthesia was used. Isoflurane (2\%) was delivered at a rate of $21 / \mathrm{min}$ using a vaporizer coupled to a nonrebreathing apparatus. Each animal was manually restrained on a covered surgical table, a small feline anesthesia mask was placed over the nose and mouth of the monkey and maintained in this position while isoflurane was administered. At the end of the procedure, the mask was removed and the animal was returned to its home cage.

\section{Statistics}

A mixed model repeated measures ANOVA was used to analyze the results of the route of administration study. Results of the repeated dosing studies were analyzed using a one-way analysis of variance, followed by LSD post hoc range tests, where appropriate. When group variances were unequal, Dunnett's T3 post hoc range was used. The significance of differences between means of two groups was determined using a two-tailed Student's $t$-test. Correlations were explored using Pearson's product moment correlation. Recognizing that the Pearson correlation assumes a bivariate normal distribution, and that our sample size was relatively small, we also calculated a nonparametric version of the Pearson product correlation coefficient, the Spearman's rho correlation coefficient. Results were considered significant when $p<0.05$, using a two-tailed test. Data analysis was performed using the Statistical Program for the Social Sciences (SPSS for Windows, Release 10.5). 


\section{RESULTS}

Compared to oral administration, subcutaneous administration of MDMA to squirrel monkeys led to a significantly higher peak level $\left(C_{\max }\right)$ and larger integrated area under the time-concentration curve $\left(\mathrm{AUC}_{0-6 \mathrm{~h}}\right)$ of MDMA (Figure 1). In contrast, the plasma concentration-time profile of MDMA's metabolite, MDA, was similar after the two routes of administration (Figure 1, inset). The elimination half-life $\left(t_{1 / 2}\right)$ of MDMA was comparable after oral and subcutaneous administration (s.c.: $3.5 \pm 0.9 \mathrm{~h}$; p.o.: $3.1 \pm 0.5 \mathrm{~h}$ ); the $t_{1 / 2}$ of MDA could not be calculated because plasma drug sampling was terminated before concentrations of MDA in the plasma had begun to decline $(6 \mathrm{~h}$ after MDMA administration).

In light of the observed impact of route of administration on MDMA's plasma concentration-time profile in squirrel monkeys, and given the fact that humans invariably take MDMA orally rather than systemically (Hegadoren et al,
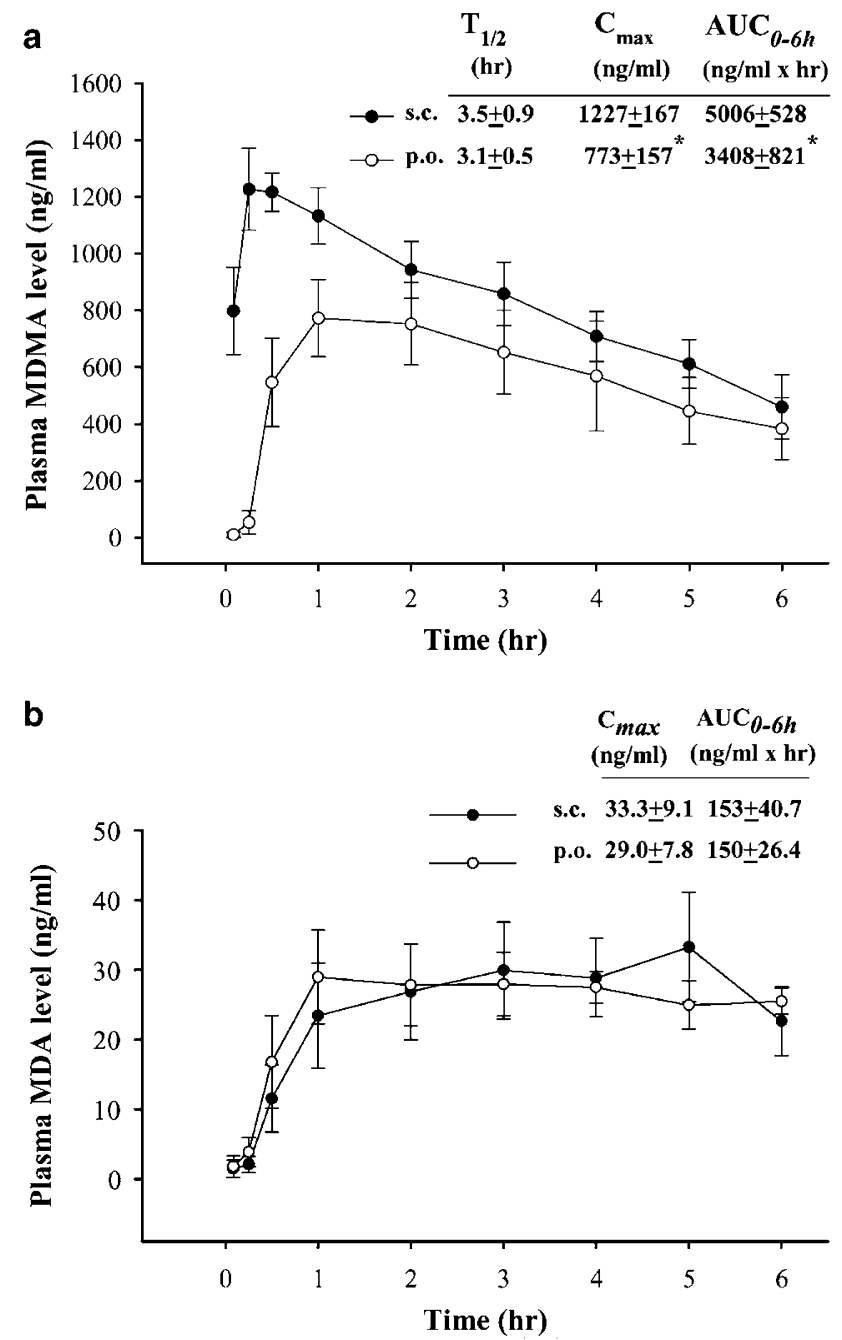

Figure I Plasma concentrations of MDMA and MDA in squirrel monkeys following administration of a single dose of MDMA by either an oral or subcutaneous route. Squirrel monkeys were administered MDMA at a dose of $7.4 \mathrm{mg} / \mathrm{kg}$. Blood was collected at various intervals after drug administration for determination of plasma concentrations of MDMA (a) and MDA (b). Results are shown as mean $\pm \operatorname{SEM}(n=4)$. *Designates significant difference from subcutaneous route, $P<0.05$.
1999; Cole and Sumnall, 2003), we performed a doseranging study using the oral route of administration. Principal outcome measures were markers of brain monoaminergic neurons 2 weeks after the last dose of MDMA. These studies were carried out in drug-naïve squirrel monkeys. Animals ( $n=3-6$ per group) received a total of three equal oral doses of MDMA, at $3 \mathrm{~h}$ intervals, at one of four dosing levels $(2.4,4.3,6.4$, or $8.6 \mathrm{mg} / \mathrm{kg})$. This particular repeated dosing regimen of MDMA was employed in order to simulate a common human recreational MDMA use pattern (Weir, 2000; Irvine et al, 2003; Parrott, 2005). At 2 weeks after MDMA treatment, monkeys showed dose-related reductions in regional brain 5-HT, 5-HIAA, and the 5-HTT (Figure 2a, b and c, respectively). There were no significant effects of MDMA on brain dopamine (DA), at any of the doses tested (Figure 2d). The lowest dose regimen of MDMA $(2.4 \mathrm{mg} / \mathrm{kg}$ regimen) produced significant serotonergic deficits in the hippocampus, temporal cortex, and olfactory tubercle; higher dose regimens of MDMA $(4.3 \mathrm{mg} / \mathrm{kg}$ and above) produced greater effects in additional brain regions (Figure 2). At the higher doses, MDMAinduced serotonergic deficits appeared to plateau at approximately $50-60 \%$.

Having characterized the dose-response function of repeated oral doses of MDMA in non-human primates, we next examined the relationship between plasma MDMA concentrations and MDMA-induced serotonergic deficits, with an eye toward determining how plasma concentrations of MDMA that produce lasting serotonergic deficits in monkeys compare to those that develop in recreational 'ecstasy' users. For these studies, different groups of monkeys ( $n=3$ per group) were treated with three of the four dose regimens of MDMA used above (2.4, 4.3, and $6.4 \mathrm{mg} / \mathrm{kg}$ regimens). Measurements of MDMA and MDA plasma concentrations at regular intervals after drug administration revealed dose- and time-related increases (Figure 3a, Table 1), with evidence of a plateau effect at the higher doses. In particular, after the two higher dose regimens $\left(4.3\right.$ and $6.4 \mathrm{mg} / \mathrm{kg}$ ), neither the $C_{\max }$ values $(2069 \pm 314$ and $2359 \pm 172 \mathrm{ng} / \mathrm{ml}$, respectively) nor the $\mathrm{AUC}_{0-9 \mathrm{~h}}\left(9422 \pm 1145\right.$ and $11444 \pm 512 \mathrm{ng} \mathrm{ml}^{-1} \mathrm{~h}$, respectively) were significantly different from one another. Squirrel monkeys metabolized MDMA to MDA, with a ratio of $\mathrm{MDA}$ to MDMA of approximately 3-5/100 (Figure 3a, Table 1). As in our initial study (Figure 2), MDMA produced dose-related serotonergic deficits 2 weeks later (Figure $3 b$ ), again with evidence of a plateau effect at the higher doses.

Analysis of the relationship between plasma drug concentrations and the extent of regional brain 5-HT depletion observed 2 weeks later showed high and direct correlations for the $C_{\max }$ and $\mathrm{AUC}_{0-9 \mathrm{~h}}$ of MDMA (Figure 3c). There was also a high correlation for the $C_{\max }$ of MDA, but not for its $\mathrm{AUC}_{0-9 \mathrm{~h}}$ (not shown).

Notably, squirrel monkeys showed evidence of nonlinear MDMA accumulation, with MDMA levels exceeding those anticipated if the effects of increasing or repeated doses were simply additive (Figure $3 \mathrm{a}$, Table 1).

To determine if three sequential doses of MDMA are necessary to produce serotonergic deficits 2 weeks later in monkeys, we tested the effects of two sequential doses. We used a dose of $4.3 \mathrm{mg} / \mathrm{kg}$; p.o, administered twice, with $3 \mathrm{~h}$ 


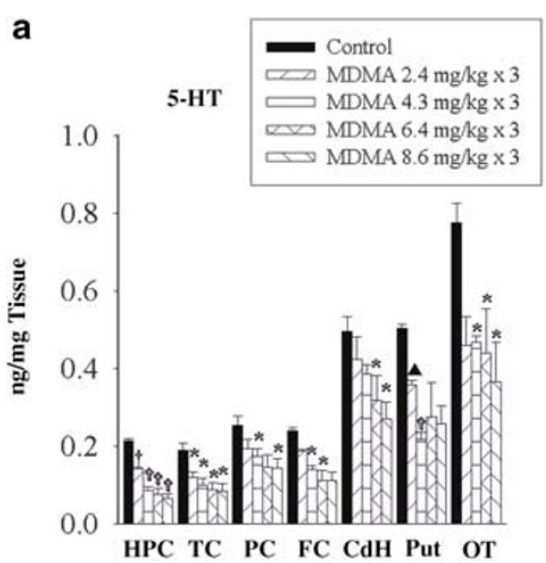

d

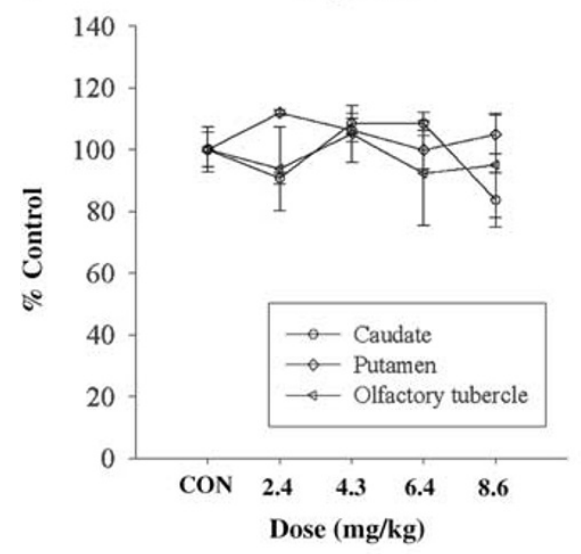

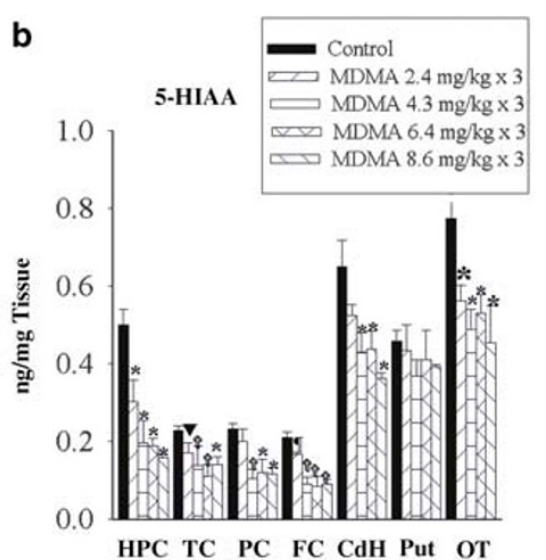

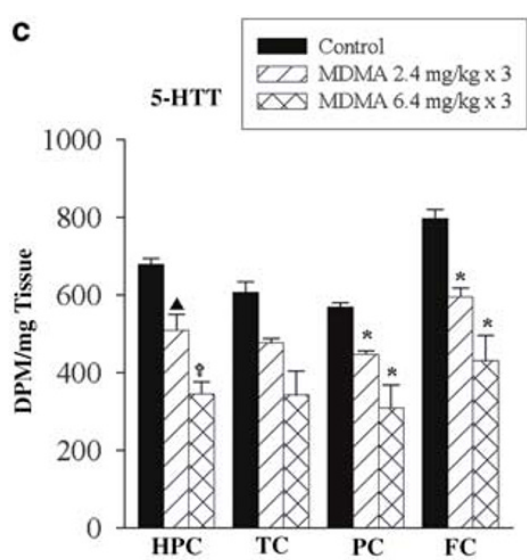

$\left[{ }^{125}\right.$ I]RTI-55 Binding

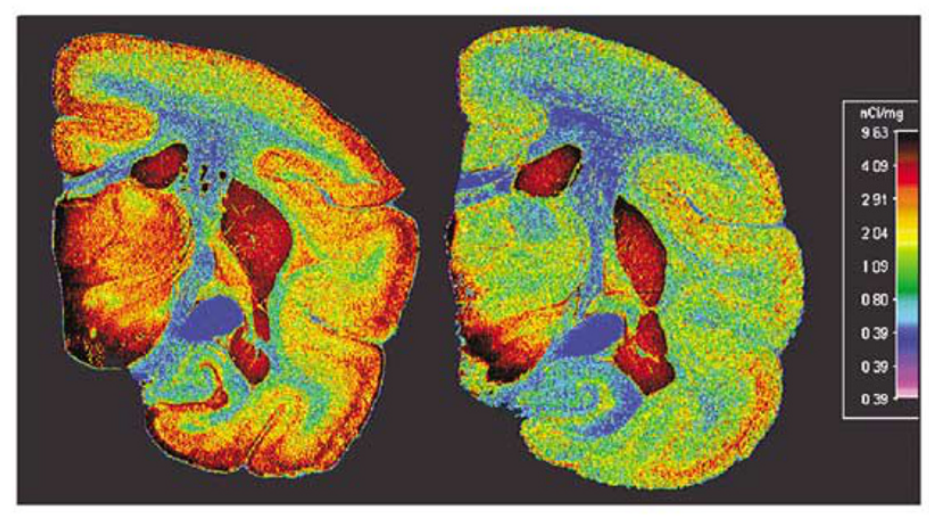

CONTROL

MDMA

Figure 2 Effect of different repeated oral doses of MDMA on regional brain 5-HT (a), 5-HIAA (b), serotonin transporter (5-HTT) (c), DA (d), and $\left[{ }^{25} \mid\right]$ RTI-55-labeled binding sites (e) in squirrel monkeys 2 weeks after drug treatment. Each dose of MDMA was tested in a different group of drug-naive squirrel monkeys, and was administered three times, at $3 \mathrm{~h}$ intervals. Results shown are the mean \pm SEM $(n=3-5$ per group). *Designates significant difference from control; Designates significant difference from control and $2.4 \mathrm{mg} / \mathrm{kg}$ group; Designates significant difference from control and $4.3 \mathrm{mg} / \mathrm{kg}$ group; Designates significant difference from control, 4.3 and $6.4 \mathrm{mg} / \mathrm{kg}$ groups; "Designates significant difference from 4.3, 6.4, and 8.6 mg/kg groups; ${ }^{\prime}$ Designates significant difference from control, 4.3, 6.4, and $8.6 \mathrm{mg} / \mathrm{kg}$ groups. (e) [ $\left.{ }^{125} \mathrm{l}\right] \mathrm{RTI}-55$-labeled binding site distribution is shown in a coronal plane of a brain from a control monkey and a monkey treated with MDMA (4.3 mg/kg regimen, as above), 2 weeks previously. Scale on right shows density of binding sites designated by color expressed in $\mathrm{nCi} / \mathrm{mg}$ tissue. Note reductions in [ $\left.{ }^{125} \mathrm{I}\right] \mathrm{RTI}-55$ binding in 5-HT innervated regions such as hippocampus, temporal cortex, and dorsal neocortex; also note lack of change in the caudate and putamen, where ${ }^{125}$ I]RTI-55 binding is predominately to DA transporters. HPC: hippocampus; TC: temporal cortex; PC: parietal cortex; FC: frontal cortex; CdH: caudate (head); PUT: putamen; OT: olfactory tubercle.

interval between doses. As shown in Figure 4, two doses of MDMA also produced significant 5-HT deficits 2 weeks later.

To ascertain if anesthesia, used to facilitate blood sampling in the studies detailed above, might have influenced the metabolism of MDMA and, potentially, altered its plasma concentrations, we compared plasma concentrations of MDMA and MDA in monkeys that underwent blood sampling with and without isoflurane anesthesia. Results of these studies showed no significant anesthesia effect. In particular, plasma levels of MDMA and MDA were nearly identical with and without isoflurane anesthesia (Figure 5).

\section{DISCUSSION}

The overall aim of the present study was to further bridge the gap between controlled animal studies of MDMA in the research laboratory and the recreational 'ecstasy' use in the community. To this end, we examined the pharmacokinetic profile of MDMA after oral administration, and tested the effects of an MDMA dosing regimen intended to simulate a recreational use pattern. We also explored the relationship between acute plasma MDMA concentrations and decrements in 5-HT neuronal markers 2 weeks later. Principal findings are discussed, in turn, below.

\section{Route of Administration}

Comparison of plasma concentration-time profiles of MDMA after oral vs subcutaneous administration revealed distinct differences. Specifically, compared to subcutaneous administration, oral administration produced a slower and significantly lower $C_{\max }$, as well as a smaller $\mathrm{AUC}_{0-6 \mathrm{~h}}$, of MDMA. Interestingly, the time-concentration profile of MDA, a metabolite of MDMA in animals and humans, was similar after both routes of MDMA administration. What influence, if any, these pharmacokinetic differences exert on MDMA's lasting serotonergic effects is presently unclear. However, they raise the possibility that MDA, known to 


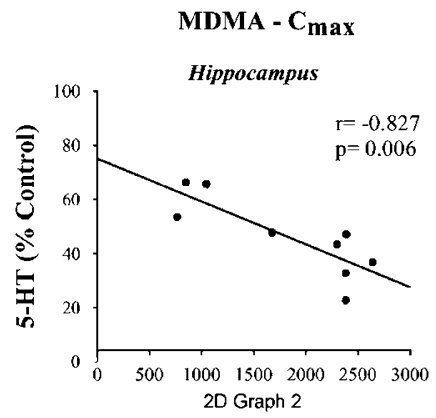

Correlations
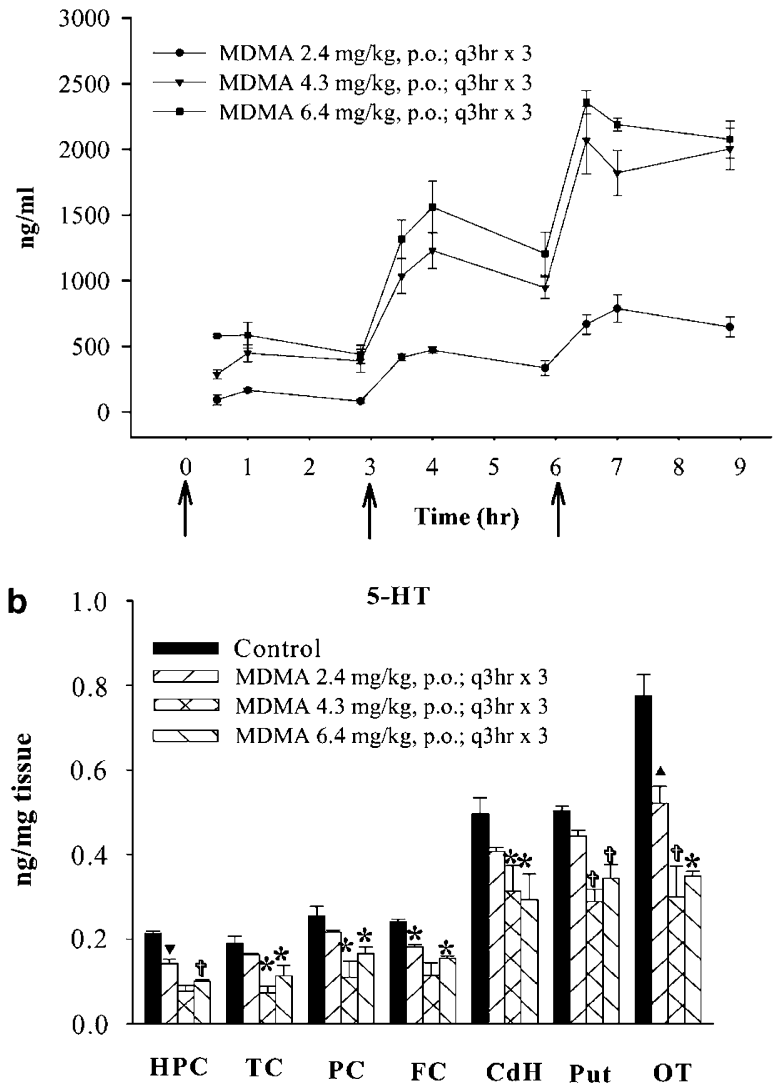
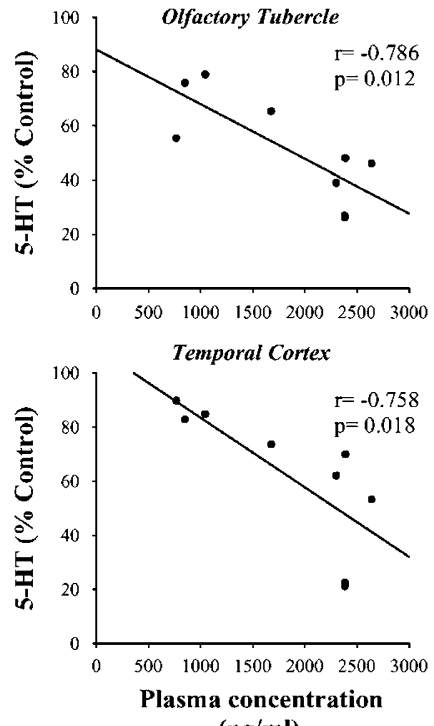

(ng/ml)
MDMA - $\mathrm{AUC}_{0-9 h}$
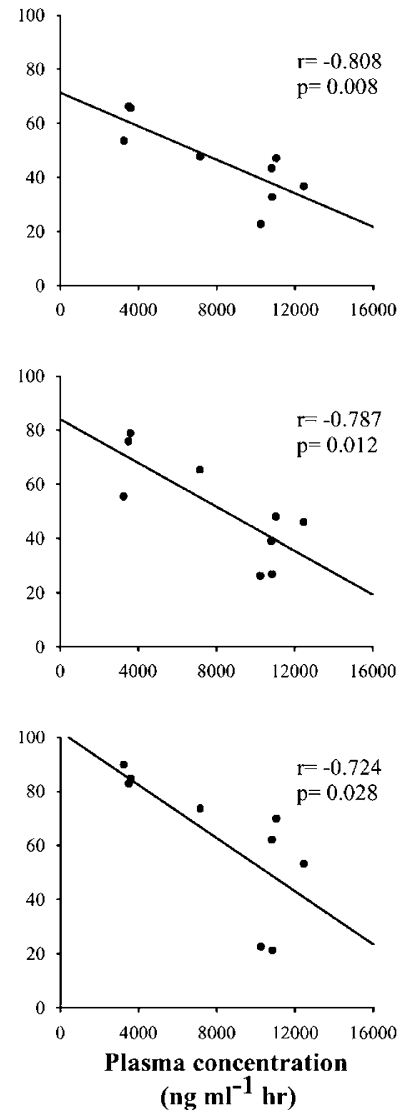

Figure 3 Plasma MDMA concentrations (a), regional brain serotonin $(5-H T)$ levels $(b)$, and correlations between peak plasma concentrations $\left(C_{\text {max }}\right)$ and area under the time-concentration curve ( $\mathrm{AUC}_{0-9 \mathrm{~h}}$ ) and regional brain 5-HT deficits (c) in squirrel monkeys administered MDMA 2 weeks previously. MDMA was administered orally in doses ranging from 2.4 to $6.4 \mathrm{mg} / \mathrm{kg}$. Each dose was administered three times, at $3 \mathrm{~h}$ intervals. Results shown are the mean \pm SEM ( $n=3-5$ per group). For determination of plasma MDMA concentrations, blood was collected at various intervals after each dose. After 2 weeks, the animals were killed for determination of regional brain 5-HT neuronal markers. *Designates significant difference from control; Designates

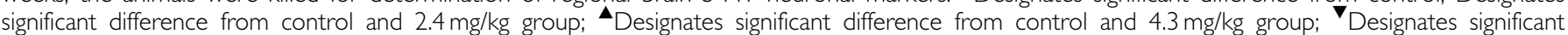
difference from control, 4.3 and $6.4 \mathrm{mg} / \mathrm{kg}$ groups; 'Designates significant difference from 4.3, 6.4, and $8.6 \mathrm{mg} / \mathrm{kg}$ groups; 'Designates significant difference from control, 4.3, 6.4, and $8.6 \mathrm{mg} / \mathrm{kg}$ groups. HPC: hippocampus; TC: temporal cortex; PC: parietal cortex; FC: frontal cortex; CdH: caudate; PUT: putamen; $\mathrm{OT}$ : olfactory tubercle. $\mathrm{R}=$ Pearson correlation coefficient. Similarly, high correlations were observed with Spearman's rho correlation coefficient (not shown).

have toxic potential toward brain 5-HT neurons (Ricaurte et al, 1985), may be more closely linked to long-term effects of MDMA, because most previous studies indicate that route of administration does not substantially impact MDMA's lasting serotonergic effects (Slikker et al, 1988, 1989; Finnegan et al, 1988; Kleven et al, 1989; Insel et al, 1989; Ali et al, 1993), although one study showed modest increases in 5-HT deficits after subcutaneous administration (Ricaurte et al, 1988a). Alternatively, sustained concentrations of MDMA (or MDA) hours after administration, rather than initial high peak MDMA levels, such as those seen after subcutaneous administration (Figure 1), may be more closely related to the neurotoxic process. Regardless of which pharmacokinetic parameter is most closely linked to MDMA's long-term effects, the pharmacokinetic profile differences presently observed suggest that, if a goal is to elucidate possible long-term effects of MDMA in humans, the oral route of administration may be preferable in preclinical studies, because it avoids the higher initial MDMA $C_{\max }$, as well as the greater AUC, observed after subcutaneous administration, and because it engenders a pharmacokinetic profile that more closely resembles that seen in humans (Helmlin et al, 1996; de la Torre et al, 2000, 2004; Pacifici et al, 2002). Although in our initial route of administration/pharmacokinetic study we cannot definitively exclude an order effect (because the subcutaneous route was tested before the oral route), we do not believe it accounts for the observed differences because, on average, 8 weeks had elapsed between subcutaneous and oral MDMA testing (Table 1).

\section{Repeated Oral Doses and Nonlinear MDMA Accumulation}

Repeated oral dosing of MDMA, intended to simulate a common recreational use pattern (Weir, 2000; Irvine et al, 
a
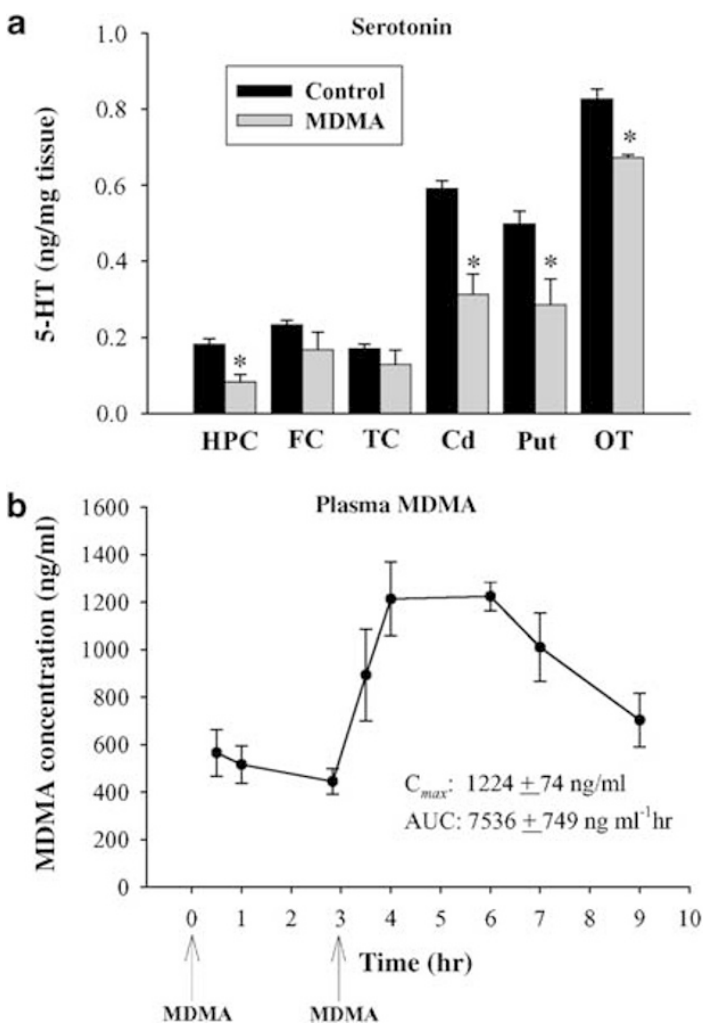

Figure 4 Regional brain serotonin $(5-H T)$ (a) and plasma MDMA concentrations (b) in squirrel monkeys $(n=3)$ administered two doses of MDMA 2 weeks previously. MDMA was administered orally at a dose of $4.3 \mathrm{mg} / \mathrm{kg}$. There was a $3 \mathrm{~h}$ interval between the two doses. Arrows designate time of MDMA administration. Results shown are the mean \pm SEM. For determination of plasma MDMA concentrations, blood was collected at various intervals after each dose. *Designates significant difference from control $(P<0.05)$. HPC: hippocampus; TC: temporal cortex; PC: parietal cortex; FC: frontal cortex; $\mathrm{CdH}$ : caudate; PUT: putamen; OT: olfactory tubercle.

2003; Parrott, 2005), produced dose-related serotonergic deficits in monkeys 2 weeks later. Further, measurement of MDMA plasma concentrations revealed dose- and timerelated increases, with increases in plasma MDMA levels after single doses ranging from 2.4 to $7.4 \mathrm{mg} / \mathrm{kg}$ and repeated doses of 2.4 and $6.4 \mathrm{mg} / \mathrm{kg}$ exceeding those that would be expected based solely upon the aggregate increase in dose (Table 2, Figure 3a). These results are in agreement with previous findings in rodents indicating that MDMA has a propensity to accumulate in a nonlinear fashion, both in plasma and brain (Chu et al, 1996). These results are also in line with findings in humans suggesting nonlinear MDMA accumulation after single doses of increasing magnitude $(50-150 \mathrm{mg}$ ) (de la Torre et al, 2000), as well as after repeated doses of the same magnitude (two doses of $100 \mathrm{mg}$ given $4 \mathrm{~h}$ apart) (Pacifici et al, 2001; Farre et al, 2004). In contrast to MDMA, MDA (a metabolite of MDMA), did not accumulate in a nonlinear fashion, which is in keeping with recent evidence of mechanism-based inactivation of $\mathrm{CYP}_{450}$ 2D6 enzyme activity by MDMA (Heydari et al, 2004).

Of note, after repeated oral dosing, plasma MDMA concentrations (Figure 3a) and serotonergic deficits
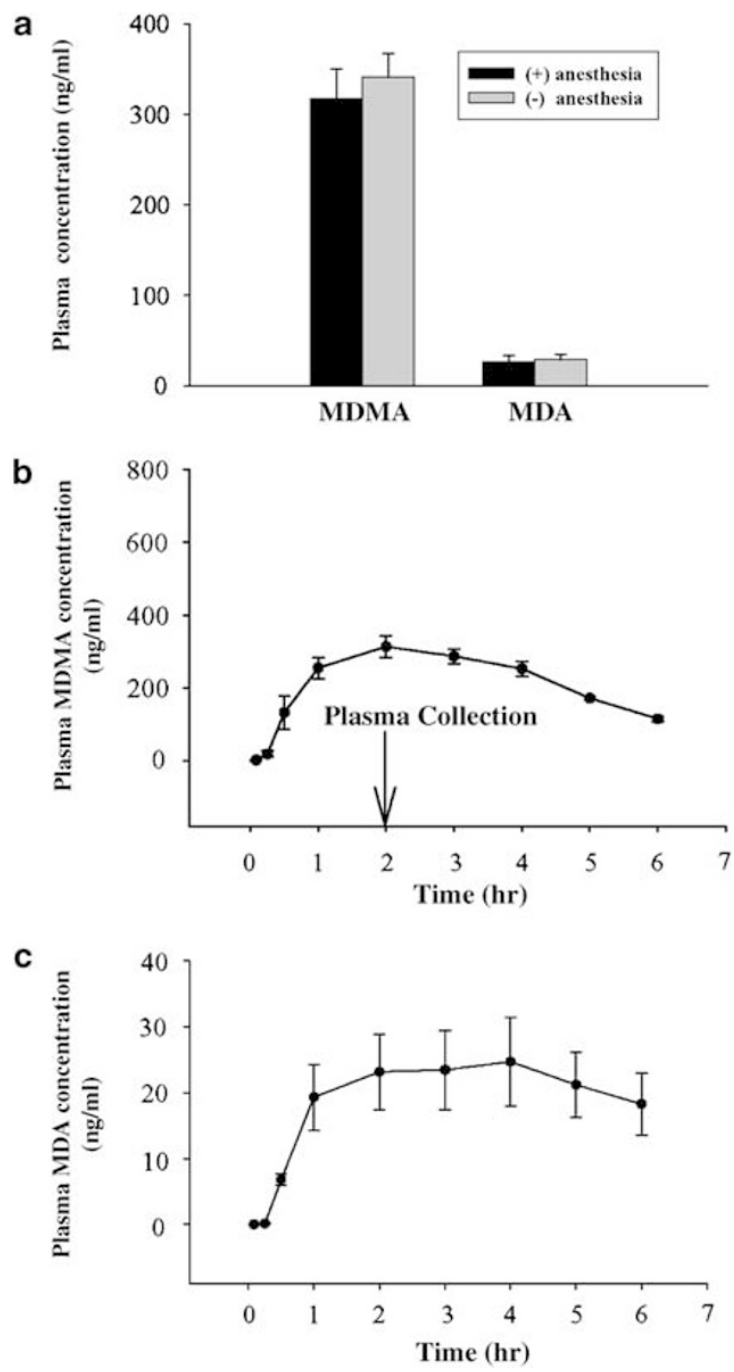

Figure 5 Comparison of plasma concentrations of MDMA and MDA after blood sampling with and without isuflurane anesthesia (a). Squirrel monkeys were administered MDMA at a dose of $3.6 \mathrm{mg} / \mathrm{kg}$, p.o. In anaesthetized monkeys $(n=4)$, blood was collected at regular intervals after MDMA administration for determination of plasma concentrations of MDMA (b) and MDA (c). In unanesthetized monkeys $(n=4)$, blood was collected $2 \mathrm{~h}$ after MDMA administration for determination of plasma concentrations of MDMA and MDA. This particular time point for plasma collection and dose of MDMA were selected because results of an initial study in anesthetized monkeys showed that plasma levels of MDMA and MDA remained relatively stable from 1.5 to $3 \mathrm{~h}$ after a $3.6 \mathrm{mg} / \mathrm{kg}$ oral dose.

(Figure 3b, and also 2a) appear to plateau with higher doses, at least those used in these experiments. We do not know why this occurs, but suspect that some aspect of the drug absorption process may become saturated. While this phenomenon is not yet understood, it is noteworthy because it underscores the fact that plasma MDMA concentration is a key determinant of subsequent effects. Specifically, although both lasting serotonergic deficits and plasma MDMA concentrations are 'dose-dependent' or 'dose-related' in a general way, it appears that, ultimately, it is the plasma drug concentration, rather than drug dose per se, that determines the extent of subsequent lasting serotonergic deficits. 
Table 2 Predicted Vs Observed AUC Values for MDMA and MDA after (A) Single Doses of MDMA of Increasing Magnitude and (B) Three Sequential Doses of MDMA of the Same Magnitude Given at $3 \mathrm{~h}$ Intervals

\begin{tabular}{|c|c|c|c|c|}
\hline \multirow[b]{2}{*}{ Dose (mg/kg) } & \multicolumn{2}{|c|}{$\begin{array}{c}\text { MDMA (AUC) } \\
\left(\mathrm{ng} \mathrm{ml}^{-1} \mathrm{~h}\right)\end{array}$} & \multicolumn{2}{|c|}{$\begin{array}{c}\text { MDA (AUC) } \\
\left(\mathrm{ng} \mathrm{ml}^{-1} \mathrm{~h}\right)\end{array}$} \\
\hline & Predicted & Observed & Predicted & Observed \\
\hline \multicolumn{5}{|l|}{ (A) Single dose } \\
\hline 2.4 & & $314 \pm 23$ & & $55 \pm 4$ \\
\hline 3.6 & 471 & $811 \pm 73$ & 82 & $75 \pm 17$ \\
\hline 4.3 & 563 & $938 \pm 204$ & 98 & $61 \pm 17$ \\
\hline 6.4 & 838 & $1373 \pm 20 \mid$ & 146 & $123 \pm 6$ \\
\hline 7.4 & 968 & $2285 \pm 444$ & 169 & $114 \pm 21$ \\
\hline
\end{tabular}

(B) Repeated doses

Levels after second dose

$\begin{array}{rrrrr}2.4 & 628 & 1442 \pm 48 & 110 & 152 \pm 63 \\ 4.3 & 1876 & 3941 \pm 575 & 122 & 170 \pm 33 \\ 6.4 & 2747 & 5211 \pm 522 & 246 & 302 \pm 19\end{array}$

Levels after third dose

$\begin{array}{rrccl}2.4 & 942 & 3451 \pm 103 & 164 & 279 \pm 15 \\ 4.3 & 2814 & 9422 \pm 1145 & 183 & 345 \pm 46 \\ 6.4 & 4120 & 11444 \pm 512 & 369 & 500 \pm 22\end{array}$

'Predicted' AUC values assume simple cumulative or additive effects of dose increments and do not take into account expected metabolic degradation.

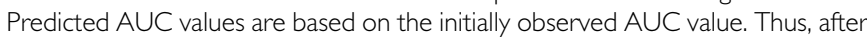
observing an $\mathrm{AUC}_{0-3 \mathrm{~h}}$ of $314 \mathrm{ng} / \mathrm{ml} \mathrm{h}$ after a single $2.4 \mathrm{mg} / \mathrm{kg}$ dose of MDMA, the predicted AUC after the $7.4 \mathrm{mg} / \mathrm{kg}$ dose would be $7.4 / 2.4 \times 314 \mathrm{ng} / \mathrm{ml} \mathrm{h}$, or $968 \mathrm{ng} / \mathrm{ml} \mathrm{h}$. As is evident from the data below, the observed AUC values after single doses of increasing magnitude were consistently higher than those predicted. For repeated or sequential doses, observed AUC values were also consistently higher than expected concentrations. For example, after the first dose of $2.4 \mathrm{mg} / \mathrm{kg}$, a plasma concentration of $314 \mathrm{ng} / \mathrm{ml} \mathrm{h}$ was observed; therefore, the predicted $A \cup C$ after the second dose of $2.4 \mathrm{mg} / \mathrm{kg}$ (again, not taking into account expected metabolic degradation) would be $314 \mathrm{ng} / \mathrm{ml} \mathrm{h} \times 2$, or $628 \mathrm{ng} / \mathrm{ml} \mathrm{h}$. As can be seen above, the observed $A_{U} C_{0-6 h}$ was $1442 \mathrm{ng} / \mathrm{ml} \mathrm{h}$, again suggesting nonlinear MDMA accumulation. Note that the same is not the case for MDA (except, possibly, after third dose). Please note that single dose data for the 3.6 and $7.4 \mathrm{mg} / \mathrm{kg}$ doses was derived from the anesthesia and route of administration studies, respectively.

\section{Correlation between Plasma MDMA Levels and Lasting Brain 5-HT Deficits}

The present data indicate that plasma concentrations of MDMA are highly correlated with regional brain 5-HT depletions observed 2 weeks later (Figure 3c). To our knowledge, this is the first such demonstration, one that raises the possibility that plasma MDMA concentration may be an good predictor of possible long-term effects of MDMA in humans. At first glance, our results in non-human primates seem at odds with those of Chu et al (1996) in rats, where no significant correlation between MDMA level and 5-HT concentration was observed. However, as emphasized by those authors, they measured 5-HT levels acutely (ie within hours after MDMA administration, at a time when 5-HT content is not necessarily an indicator of 5-HT axon terminal integrity), whereas we measured 5-HT neuronal markers 2 weeks after MDMA.

\section{Comparison to Plasma MDMA Concentrations in 'Ecstasy' Consumers}

Published reports (Peters et al, 2003; Lora-Tamayo et al, 2004; also see Samyn et al, 2002) indicate that some recreational 'ecstasy' consumers who come to the attention of authorities have plasma concentrations of MDMA that overlap those seen here, in monkeys that subsequently develop lasting deficits in brain 5-HT neuronal markers. Findings in asymptomatic 'ecstasy' consumers of (Irvine et al, unpublished observations) are in general agreement with those in symptomatic individuals who presented to emergency rooms, or for some reason (eg driving impairment) came to the attention of authorities in the wake of 'ecstasy'/MDMA use. Knowledge of plasma MDMA concentrations in individuals who use 'ecstasy' in a recreational setting may be particularly relevant, because variables unique to the setting of drug ingestion (dance party) could influence plasma MDMA concentrations, as well as its metabolism and, possibly, its acute and long-term effects.

\section{Comparison to Laboratory Human Studies}

Comparison of plasma profiles of MDMA and MDA in squirrel monkeys to those previously reported in humans given MDMA in a controlled laboratory setting reveals similarities and differences. As indicated above, nonlinear MDMA accumulation appears to take place in both squirrel monkeys and humans (de la Torre et al, 2000; Pacifici et al, 2001; Farre et al, 2004). The plasma ratio of MDA to MDMA, 3-5/100, is also similar in the two species (de la Torre et al, 2000; Pacifici et al, 2002; Farre et al, 2004). One difference appears to be that 'equivalent' single doses produce higher plasma concentrations of MDMA in the squirrel monkey than in the human. For example, the $7.4 \mathrm{mg} / \mathrm{kg}$ dose in the monkey, estimated to be comparable to a $2 \mathrm{mg} / \mathrm{kg}$ dose in a human by the allometric method (for discussion of the method, including its limitations, see Mordenti and Chappell, 1989; Ings, 1990; Boxenbaum and DiLea, 1995; Mahmood, 2002; Mahmood et al, 2003) produced a $C_{\max }$ of $773 \mathrm{ng} / \mathrm{ml}$ (Figure 1), whereas the 'equivalent' dose in humans $(150 \mathrm{mg}$ given to two subjects weighing approximately $75 \mathrm{~kg}$ ) produced a $C_{\max }$ ranging from 442 to $487 \mathrm{ng} / \mathrm{ml}$ (de la Torre et al, 2000). The higher plasma MDMA concentration in squirrel monkeys than humans could reflect limits of sample size, limitations of interspecies dose scaling methods using an allometric equation, or effects of stress of our experimental procedures (Johnson et al, 2004).

\section{Effect of Two Sequential Doses}

In monkeys, sequential or closely spaced repeated dosing (and the consequent sustained levels of MDMA and/or MDA, Figure 3a) is likely to have played a role in the observed lasting serotonergic deficits. However, three sequential doses of MDMA do not appear to be necessary 
to produce long-term (2 weeks) effects, since two sequential doses $(4.3 \mathrm{mg} / \mathrm{kg}$; p.o.; 3-h interval between doses) also produced lasting serotonergic deficits (Figure 5). As evidenced by subjects who participated in a recent clinical study conducted in a naturalistic setting (Irvine et al, 2003), recreational 'ecstasy' users often use sequential doses hours apart, suggesting that our findings in non-human primates may be relevant to such individuals. However, additional studies (using single and repeated doses) in non-human primates are necessary to further assess the risks associated with MDMA exposure, and future clinical and preclinical research should address potentially important differences between single and multiple doses of MDMA, both with regard to pharmacokinetics and long-term effects.

\section{'Threshold' Level}

The present studies do not permit conclusive statements about a 'threshold' plasma concentration of MDMA associated with brain serotonergic neurotoxicity, because even the lowest dose regimen tested produced lasting serotonergic effects, and because our sample size of nonhuman primates was necessarily small. However, mean $( \pm S D)$ peak plasma MDMA concentrations after the lowest repeated dose regimen that produced long-term effects were $787 \pm 129 \mathrm{ng} / \mathrm{ml}$ (range: 654 to $1046 \mathrm{ng} / \mathrm{ml}$, Figure 3). As mentioned above, these plasma MDMA concentrations overlap those found in some recreational 'ecstasy' consumers. Further, they are two to three times higher than maximal concentrations $\left(C_{\max }\right)$ that develop in humans (190-487 $\mathrm{ng} / \mathrm{ml}$ ) administered a single $100-150 \mathrm{mg}$ dose of MDMA in a controlled laboratory setting (Helmlin et al, 1996; de la Torre et al, 2000, 2004; Pacifici et al, 2001, 2002; Kraemer and Maurer, 2002). The dose of MDMA required to produce desired subjective effects in humans ranges from 80 to $160 \mathrm{mg}$ (Anderson et al, 1978). Although we do not yet know which pharmacokinetic parameter is most closely linked to MDMA's long-term effects, it appears that plasma MDMA concentrations in recreational users are on the order of those that produce lasting serotonergic deficits in non-human primates (present study) and rodents (Colado et al, 1995).

\section{Study Limitations}

Several potential limitations of our studies should be recognized. First, the full significance of the relationship between plasma concentrations of MDMA (and/or MDA) and lasting serotonergic deficits is uncertain, because the mechanism of MDMA-induced toxicity toward brain 5-HT neurons requires a better understanding. Second, MDMA is biotransformed to metabolites that were not measured in this study (3, 4-dihydroxymethamphetamine (HHMA) and 4-hydroxy- 3-methoxymethamphetamine (HMMA)), and these metabolites could be implicated in MDMA's longterm effects (if they cross the blood-brain barrier in their conjugated form or if they are formed centrally) (see Jones et al, 2005). Third, some aspect of MDMA metabolism in squirrel monkeys and humans may differ, although nonlinear MDMA accumulation and comparable proportions of MDA and MDMA are observed in both species. Fourth, the threshold oral dose of MDMA that elicits physiological effects in squirrel monkeys is not known; thus, a point of reference for toxic doses of MDMA in squirrel monkeys is currently unavailable, although in other non-human primate species behaviorally active doses range from 0.01 to $5.6 \mathrm{mg} / \mathrm{kg}$ (depending on route and frequency of administration and outcome measure in question (Kamien et al, 1986; Thompson et al, 1987; Slikker et al, 1989; Frederick and Paule, 1997; Fantegrossi et al, 2004)).

\section{Conclusions}

Route of administration influences the pharmacokinetic profile of MDMA, but not that of its metabolite, MDA. Repeated oral administration of MDMA to squirrel monkeys results in dose-related serotonergic deficits 2 weeks later. MDMA (but not MDA) accumulates in a nonlinear fashion in squirrel monkeys, and peak levels are highly correlated with lasting serotonergic deficits documented in the same animals 2 weeks later. Plasma MDMA concentrations associated with lasting effects on brain 5-HT neurons in squirrel monkeys overlap those found in some recreational 'ecstasy' consumers, and are only two to three times higher than those that develop in humans given a single $100-150 \mathrm{mg}$ dose of MDMA in a controlled setting. Additional research is needed to determine the relative sensitivity of human and monkey brain 5-HT neurons to MDMA, the pharmacokinetic parameter(s) of MDMA or its metabolites most closely linked to the neurotoxic process, and metabolites other than MDA that may play a role.

\section{ACKNOWLEDGEMENTS}

We thank Christopher Mehl for his guidance in using the pharmacokinetic program (Pharsight Corp., Mountain View, CA). Portions of this work were presented in abstract form (G Ricaurte, International Congress of Therapeutic Drug Monitoring and Clinical Toxicology, Basel, Switzerland, September 2003). This work was supported by USPHS Grants DA5707 and DA00206 (GAR) and the National Health and Medical Research Council of Australia (RJI).

\section{REFERENCES}

Ali SF, Newport GD, Scallet AC, Binienda Z, Ferguson SA, Bailey JR et al (1993). Oral administration of 3,4-methylenedioxymethamphetamine (MDMA) produces selective serotonergic depletion in the nonhuman primate. Neurotoxicol Teratol 15: 91-96.

Anderson GM, Braun G, Braun U, Nichols DE, Shulgin AT (1978). Absolute configuration and psychomimetic activity. NIDA Res Monogr 22: 8-15.

Axt K, Mamounas L, Molliver M (1994). Structural features of amphetamine neurotoxicity. In: Cho AK, Segal DS (eds). Amphetamine and its Analogs. Academic Press: San Diego, CA. pp 315-370.

Battaglia G, Yeh SY, O’Hearn E, Molliver ME, Kuhar MJ, Desouza EB (1987). 3,4-Methylenedioxymethamphetamine and 3,4-methylenedioxyamphetamine destroy serotonin terminals in rat brain: quantification of neurodegeneration by measurement of ${ }^{3} \mathrm{H}$ paroxetine-labeled serotonin uptake sites. J Pharmacol Exp Ther 242: 911-916.

Bendotti C, Baldessari S, Pende M, Tarizzo G, Miari A, Presti ML et al (1994). Does GFAP mRNA and mitochondrial benzodiaze- 
pine receptor binding detect serotonergic neuronal degeneration in rat? Brain Res Bull 34: 389-394.

Bowyer JF, Young JF, Slikker W, Itzak Y, Mayorga AJ, Newport GD et al (2003). Plasma levels of parent compound and metabolites after doses of either $d$-fenfluramine or $d$-3,4-methylenedioxymethamphetamine (MDMA) that produce long-term serotonergic alterations. Neurotoxicology 24: 379-390.

Boxenbaum H, DiLea C (1995). First-time-in-human dose selection: allometric thoughts and perspectives. J Clin Pharmacol 35: 957-966.

Callahan BT, Cord BJ, Ricaurte GA (2001). Long-term impairment of anterograde axonal transport along fiber projections originating in the rostral raphe nuclei after treatment with fenfluramine or methylenedioxymethamphetamine. Synapse 40: 113-121.

Chu T, Kumagai Y, DiStefano EW, Cho AK (1996). Disposition of methylenedioxymethamphetamine and three metabolites in the brains of different rat strains and their possible roles in acute serotonin depletion. Biochem Pharmacol 51: 789-796.

Colado MI, Williams JL, Green AR (1995). The hyperthermic and neurotoxic effects of 'Ecstasy' (MDMA) and 3,4-methylenedioxyamphetamine (MDA) in the Dark Agouti (DA) rat, a model of the CYP2D6 poor metabolizer phenotype. Br J Pharmacol 115: 1281-1289.

Cole JC, Sumnall HR (2003). The pre-clinical behavioural pharmacology of 3,4-methylenedioxymethamphetamine (MDMA). Neurosci Biobehav Rev 27: 199-217.

de la Torre R, Farre M, Ortuno J, Mas M, Brenneisen R, Roset PN et al (2000). Non-linear pharmacokinetics of MDMA ('ecstasy') in humans. Br J Clin Pharmacol 49: 104-109.

de la Torre R, Farre M, Roset PN, Pizarro N, Abanades S, Segura M et al (2004). Human pharmacology of MDMA: pharmacokinetics, metabolism, and disposition. Ther Drug Monit 26: 137-144.

Degenhardt L, Barker B, Topp L (2004). Patterns of ecstasy use in Australia: findings from a national household survey. Addiction 99: 187-195.

EMCDDA (2003). European Monitoring Centre for Drugs and Drug Addiction: the state of the drugs problem in the European Union and Norway: annual report. Available online at: http:// annualreport.emcdda.eu.int.

Fantegrossi WE, Woolverton WL, Kilbourn M, Sherman P, Yuan J, Hatzidimitriou G et al (2004). Behavioral and neurochemical consequences of long-term intravenous self-administration of MDMA and its enantiomers by rhesus monkeys. Neuropsychopharmacology 29: 1270-1281.

Farre M, de La Torre R, Mathuna BO, Roset PN, Peiro AM, Torrens $M$ et al (2004). Repeated doses administration of MDMA in humans: pharmacological effects and pharmacokinetics. Psychopharmacology 173: 364-375.

Finnegan KT, Ricaurte GA, Ritchie LD, Irwin I, Peroutka SJ, Langston JW (1988). Orally administered MDMA causes a longterm depletion of serotonin in rat brain. Brain Res 447: 141-144.

Fischer CA, Hatzidimitriou G, Wlos J, Katz JL, Ricaurte GA (1995). Reorganization of ascending 5-HT axon projections in animals previously exposed to the recreational drug $( \pm) 3,4$-methylenedioxymethamphetamine (MDMA, 'Ecstasy'). J Neurosci 15: 5476-5485.

Frederick DL, Paule MG (1997). Effects of MDMA on complex brain function in laboratory animals. Neurosci Biobehav Rev 21: 67-78.

Gibb JW, Hanson GR, Johnson M (1994). Neurochemical mechanisms of toxicity. In: Cho AK, Segal DS (eds). Amphetamine and its Analogs. Academic Press: San Diego, CA. pp 269-295.

Green AR, Mechan AO, Elliott JM, O'Shea E, Colado MI (2003). The pharmacology and clinical pharmacology of 3,4-methylenedioxymethamphetamine (MDMA, 'ecstasy'). Pharmacol Rev 55: 463-508.
Hegadoren KM, Baker GB, Bourin M (1999). 3,4-Methylenedioxy analogues of amphetamine: defining the risks to humans. Neurosci Biobehav Rev 23: 539-553.

Helmlin HJ, Bracher K, Bourquin D, Vonlanthen D, Brenneisen R (1996). Analysis of 3,4-methylenedioxymethamphetamine (MDMA) and its metabolites in plasma and urine by HPLCDAD and GC-MS. J Anal Toxicol 20: 432-440.

Herráez-Hernández R, Campíns-Falcó P, Verdú-Andrés J (2001). Sensitive determination of methylenedioxylated amphetamines by liquid chromatography. Analyst 126: 581-586.

Heydari A, Rowland Yeo K, Lennard M, Ellis SW, Tucker G, Rostami-Hodjegan A (2004). The mechanism-based inactivation of CYP2D6 by methylenedioxymethamphetamine (MDMA). Drug Metab Dispos 32: 1213-1217.

Ings RM (1990). Interspecies scaling and comparison in drug development and toxicokinetics. Xenobiotica 20: 1201-1231.

Insel TR, Battaglia G, Johannessen JN, Marra S, De Souza EB (1989). 3,4-Methylenedioxymethamphetamine ('ecstasy') selectively destroys brain serotonin terminals in rhesus monkeys. $J$ Pharmacol Exp Ther 249: 713-720.

Irvine R, Keane M, Felgate P, White J (2003). Physiological effects, blood chemistry and drug concentrations in 'club drug' users at a recreational setting. Problems of Drug Dependence: Proceedings of the 65th Annual Scientific Meeting, Bal Harbour, Florida. p 70.

Johnson EA, O'Callaghan JP, Miller DB (2004). Brain concentrations of $d$-MDMA are increased after stress. Psychopharmacology 173: $278-286$.

Johnston LD, O’Malley PM, Bachman JG, Schulenberg E (2004). Monitoring the Future National Results on Adolescent Drug Use: Overview of Key Findings 2003. NIH Publication No. 04-5506. National Institute on Drug Abuse: Bethesda, MD.

Jones DC, Duvauchelle C, Ikegami A, Olsen CM, Lau SS, de la Torre $\mathrm{R}$ et al (2005). Serotonergic neurotoxic metabolites of ecstasy identified in rat brain. J Pharmacol Exp Ther 313: $422-431$.

Kalant H (2001). The pharmacology and toxicology of 'ecstasy' (MDMA) and related drugs. CMAJ 165: 917-928.

Kamien JB, Johanson CE, Schuster CR, Woolverton WL (1986). The effects of $(+/-)$-methylenedioxymethamphetamine and $(+/-)$-methylenedioxyamphetamine in monkeys trained to discriminate (+)-amphetamine from saline. Drug Alcohol Depend 18: 139-147.

Kleven MS, Woolverton WL, Seiden LS (1989). Evidence that both intragastric and subcutaneous administration of methylenedioxymethylamphetamine (MDMA) produce serotonin neurotoxicity in rhesus monkeys. Brain Res 488: 121-125.

Kraemer T, Maurer HH (2002). Toxicokinetics of amphetamines: metabolism and toxicokinetic data of designer drugs, amphetamine, methamphetamine, and their $N$-alkyl derivatives. Ther Drug Monit 24: 277-289.

Laruelle M, Baldwin R, Malison R, Zea-Ponce Y, Zoghbi S, Al-Tikriti $\mathrm{M}$ et al (1993). SPECT imaging of dopamine and serotonin transporters with [123I] $\beta$-CIT: pharmacological characterization of brain uptake in nonhuman primates. Synapse 13: 295-309.

Lew R, Malberg JE, Ricaurte GA, Seiden LS (1997). Evidence for and mechanism of action of neurotoxicity of amphetamine related compounds. In: Kostrzewa RM (ed). Highly Selective Neurotoxins: Basic and Clinical Applications. Humana Press Inc.: Totowa. pp 235-268.

Lora-Tamayo C, Tena T, Rodriguez A, Moreno D, Sancho JR, Ensenat $\mathrm{P}$ et al (2004). The designer drug situation in Ibiza. Foren Sci Int 140: 195-206.

Mahmood I (1999). Allometric issues in drug development. J Pharmaceut Sci 88: 1101-1106.

Mahmood I (2002). Interspecies scaling: predicting oral clearance in humans. Am J Ther 9: 35-42. 
Mahmood I, Green MD, Fisher JE (2003). Selection of the first-time dose in humans: comparison of different approaches based on interspecies scaling of clearance. J Clin Pharmacol 43: 692-697.

Mordenti J, Chappell W (1989). The use of interspecies scaling in toxicokinetics. In: Yacobi A, Kelly J, Batra V (eds). Toxicokinetics in New Drug Development. Pergamon Press: New York. pp 42-96.

O'Callaghan JP, Miller DB (1994). Neurotoxicity profiles of substituted amphetamines in the C57BL/6J mouse. J Pharmacol Exp Ther 270: 741-751.

O'Hearn E, Battaglia G, De Souza EB, Kuhar MJ, Molliver ME (1988). Methylenedioxyamphetamine (MDA) and methylenedioxymethamphetamine (MDMA) cause selective ablation of serotonergic axon terminals in forebrain: immunocytochemical evidence for neurotoxicity. J Neurosci 8: 2788-2803.

Pacifici R, Zuccaro P, Farre M, Pichini S, Di Carlo S, Roset PN et al (2001). Effects of repeated doses of MDMA ('ecstasy') on cellmediated immune response in humans. Life Sci 69: 2931-2941.

Pacifici R, Zuccaro P, Farre M, Pichini S, Di Carlo S, Roset PN et al (2002). Cell-mediated immune response in MDMA users after repeated dose administration: studies in controlled versus noncontrolled settings. Ann N Y Acad Sci 965: 421-433.

Parrott AC (2005). Chronic tolerance to recreational MDMA (3,4- methylenedioxymethamphetamine) or Ecstasy. J Psychopharmacol 19: 71-83.

Peters FT, Samyn N, Wahl M, Kraemer T, De Boeck G, Maurer HH (2003). Concentrations and ratios of amphetamine, methamphetamine, MDA, MDMA, and MDEA enantiomers determined in plasma samples from clinical toxicology and driving under the influence of drugs cases by GC-NICI-MS. J Anal Toxicol 27: 552-559.

Pubill D, Canudas AM, Pallas M, Camins A, Camarasa J, Escubedo E (2003). Different glial response to methamphetamineand methylenedioxymethamphetamine-induced neurotoxicity. Naunyn Schmiedebergs Arch Pharmacol 367: 490-499.

Ricaurte GA, Bryan G, Strauss L, Seiden L, Schuster C (1985). Hallucinogenic amphetamine selectively destroys brain serotonin nerve terminals. Science 229: 986-988.

Ricaurte GA, DeLanney LE, Irwin I, Langston JW (1988a). Toxic effects of 3,4-methylenedioxymethamphetamine on central serotonergic neurons in the primate: importance of route and frequency of drug administration. Brain Res 446: 165-168.

Ricaurte GA, Forno LS, Wilson MA, DeLanney LE, Irwin I, Molliver ME et al (1988b). 3,4-Methylenedioxymethamphetamine (MDMA) selectively damages central serotonergic neurons in nonhuman primates. JAMA 260: 51-55.

Ricaurte GA, Martello AL, Katz JL, Martello MB (1992). Lasting effects of $( \pm) 3,4$-methylenedioxymethamphetamine (MDMA) on central serotonergic neurons in nonhuman primates: neurochemical observations. J Pharmacol Exp Ther 261: 616-622.

Rowland NE, Kalehua AN, Li BH, Semple-Rowland SL, Streit WJ (1993). Loss of serotonin uptake sites and immunoreactivity in rat cortex after dexfenfluramine occur without parallel glial cell reaction. Brain Res 624: 35-43.

Sadeghipour F, Veuthey JL (1997). Sensitive and selective determination of methylenedioxylated amphetamines by highperformance liquid chromatography with fluorimetric detection. J Chromatogr A 787: 137-143.

Samyn N, De Boeck G, Wood M, Lamers CT, De Waard D, Brookhuis KA et al (2002). Plasma, oral fluid and sweat wipe ecstasy concentrations in controlled and real life conditions. Foren Sci Int 14; 128 90-97.

Scanzello CR, Hatzidimitriou G, Martello AL, Katz JL, Ricaurte GA (1993). Serotonergic recovery after (+/-)3,4-(methylenedioxy)methamphetamine injury: observations in rats. J Pharmacol Exp Ther 264: 1484-1491.

Schmidt CJ (1987). Neurotoxicity of the psychedelic amphetamine, methylenedioxymethamphetamine. J Pharmacol Exp Ther 240: $1-7$.

Segura M, Ortuño J, Farré M, McLure JA, Pujadas M, Pizarro N et al (2001). 3,4-dihydroxymethamphetamine (HHMA). A major in vivo 3,4-methylenedioxymethamphetamine (MDMA) metabolite in humans. Chem Res Toxicol 14: 1203-1208.

Slikker W, Ali SF, Scallet AC, Frith CH, Newport GD, Bailey JR (1988). Neurochemical and neurohistological alterations in the rat and monkey produced by orally administered methylenedioxymethamphetamine (MDMA). Toxicol Appl Pharmacol 94: 448-457.

Slikker Jr W, Holson RR, Ali SF, Kolta MG, Paule MG, Scallet AC et al (1989). Behavioral and neurochemical effects of orally administered MDMA in the rodent and nonhuman primate. Neurotoxicology 10: 529-542.

Staley J, Krishnan-Sarin S, Zoghbi S, Tamagnan G, Fujita M, Seibyl $J$ et al (2001). Gender differences in dopamine and serotonin transporter availability in healthy smokers and nonsmokers. Synapse 41: 275-284.

Steele T, McCann U, Ricaurte GA (1994). 3,4-Methylenedioxymethamphetamine (MDMA, 'Ecstasy'): pharmacology and toxicology in animals and humans. Br J Addict 89: 539-551.

Thomas DM, Dowgiert J, Geddes TJ, Francescutti-Verbeem D, Liu X, Kuhn DM (2004). Microglial activation is a pharmacologically specific marker for the neurotoxic amphetamines. Neurosci Lett 367: 349-354.

Thompson DM, Winsauer PJ, Mastropaolo J (1987). Effects of phencyclidine, ketamine and MDMA on complex operant behavior in monkeys. Pharmacol Biochem Behav 26: 401-405.

Weir E (2000). Raves: a review of the culture, the drugs and the prevention of harm. CMAJ 162: 1843-1848.

Wilson MA, Mamounas LA, Fasman KH, Axt KJ, Molliver ME (1993). Reactions of 5-HT neurons to drugs of abuse: neurotoxicity and plasticity. NIDA Res Monogr 136: 155-187.

Wilson MA, Ricaurte GA, Molliver ME (1989). Distinct morphologic classes of serotonergic axons in primates exhibit differential vulnerability to the psychotropic drug 3,4-methylenedioxymethamphetamine. J Neuroscience 28: 121-137. 